\title{
Research on the Training Method of Clinical Thinking in Human Anatomy Teaching
}

\author{
Gaigai Su* \\ Xuchang University, Xuchang 461000, China. E-mail: 754396749@qq.com
}

\begin{abstract}
Human anatomy is a science to study the normal human body shape and structure. It is an important basic medical course, and closely related to various medical disciplines, especially to clinical medicine. Under the concept of comprehensive quality education, anatomy teachers should not only impart theoretical knowledge and professional skills, but also pay attention to the cultivation of students' clinical thinking ability, so as to lay a solid foundation for students' subsequent professional study and clinical practice. This paper focuses on the training of clinical thinking in human anatomy teaching.
\end{abstract}

Keywords: Anatomy Teaching; Clinical Thinking; Training Methods; Research

Clinical thinking ability refers to the use of basic medical theory knowledge in clinical practice to make reasonable analysis, accurate research and judgment of clinical cases, and put forward targeted clinical solutions. Clinical thinking ability is one of the clinical abilities that medical students must possess, and can help students learn how to deal with various clinical problems. Under the traditional medical teaching mode, it focuses on the cultivation of students' clinical thinking ability during clinical observation and practice, but the effect is not so good. The main reason is that under the traditional examination oriented education system, the basic medical curriculum is seriously divorced from the clinical practice, and the students passively accept knowledge, losing the initiative and enthusiasm of learning, and limiting the development of logical thinking and creative thinking ability. At present, in order to cultivate more medical talents, it is necessary to train students' clinical thinking ability throughout the whole basic course teaching. Starting from human anatomy, students should be guided to play their subjective initiative, actively think and cooperate in exploration, so as to cultivate students' good clinical thinking ability while mastering professional knowledge and skills.

\section{Optimizing the teaching content of anatomy and infiltrating clinical thinking concept}

With the continuous progress of medical technology in our country and the rapid development of medicine, the content of traditional anatomy knowledge must keep pace with the times and introduce new technology and new ideas, so that students can fully master the real-time updated anatomy knowledge. Based on this, medical teachers in colleges and universities should pay attention to the latest anatomy research in real time, master new technology, knowledge and concept, and abandon the backward and wrong teaching content and concept at the first time so as to draw lessons from the latest clinical

Copyright @ 2020 Gaigai Su

doi: 10.18686/aem.v9i4.179

This is an open-access article distributed under the terms of the Creative Commons Attribution Non-Commercial License

(http://creativecommons.org/licenses/by-nc/4.0/), which permits unrestricted non-commercial use, distribution, and reproduction in any medium, provided the original work is properly cited. 
research results, strengthen the connection between anatomy teaching content and clinical medicine, and pay attention to the cultivation of science step by step in teaching clinical thinking ability, creative thinking ability. For example, when explaining the knowledge points of the "digestive system" chapter, teachers can use classic cases such as clinical duodenal ulcer and gastric ulcer to focus students' attention in class with specific and vivid clinical manifestations, promote students' deep thinking through close combination with clinical cases, and compare the similarities and differences of gastric and duodenal mucosa in anatomical structure, which is beneficial for students to understand and master the anatomical structure of duodenum and stomach, and fully grasp its clinical application scope; in addition, we can also expand the extension link to introduce the relationship between helicobacter pylori and gastropathy to students, so as to not only explain the theoretical knowledge of anatomy, but also enable students to understand clinical medical knowledge, broaden their horizons and cultivate students' comprehensive medical science ability and quality.

\section{Innovating teaching methods and stimulating students' clinical thinking consciousness}

In the process of anatomy teaching, teachers should give full play to the main role of students in teaching, build a harmonious, democratic and equal relationship between teachers and students, and adopt group cooperation, problem-oriented and task-driven teaching methods. As the organizer and director of teaching, teachers should pay attention to active classroom atmosphere, create a relaxed and pleasant teaching atmosphere, and make use of scientific and efficient teaching methods to cultivate the clinical thinking ability of the students step by step. For example, when learning the knowledge points of the chapter "appendicitis", the teacher can arrange the preview task first, so that the students can understand the position and shape of the appendix in the human body through the human body specimen in the preview process; in the classroom teaching, teacher can make full use of the video, animation, pictures and other carriers in the multimedia teaching technology, so that students can intuitively and vividly feel the human body structure of the appendix. For the organization of practical teaching, in the form of group cooperation, students can carry out appendectomy through human specimens, and in the process of their hands-on operation, teachers track the whole process and ask questions in real time. For example, what harm does acute appendicitis have? Where is the best operation position of acute appendicitis? If surgery is performed, what incision should be made? How to find appendix during operation? etc. It is important to pay attention to guide students to correctly understand the anatomical basis of appendicitis. In this way, students can learn, think and operate, effectively stimulate students' interest and enthusiasm in learning anatomy, so as to guide students to divergent thinking, cultivate their clinical thinking ability and creative thinking ability, achieving comprehensive development.

\section{Attaching importance to experi- mental teaching and building a perfect clinical practice platform}

Medical specialty is practical and skilled. Experimental teaching is an important part of human anatomy course, which plays an irreplaceable role in training students' clinical practice ability and clinical thinking ability. Human anatomy belongs to the category of morphology in biology. Therefore, we must attach importance to experimental teaching and increase the proportion of experimental teaching in the teaching process. Teachers should pay attention to the construction of a perfect experimental and practical platform, so that students can have a comprehensive and profound understanding of human anatomy knowledge, understand the human body structure, accumulate rich clinical experience, and lay a solid foundation for the follow-up career. At present, the anatomy laboratory of our college provides a variety of specimens to meet the needs of students' anatomy learning, including (box, model, plasticization, section, etc.) specimens and general specimens, which are placed in the display cabinet of each laboratory. In the specific experimental teaching process, students can find the corresponding specimens according to the learning requirements of each chapter, under the guidance of teachers, and carry out targeted learning with a careful observation $^{[1]}$. The anatomy laboratory of our college is open all day (except winter and summer vacation), and students 
can enter and leave freely, which provides great convenience for students' experimental study. In addition, in the experimental teaching, teachers should not leave the students alone, should increase the interaction with students, and point out the problems encountered in the process of observing specimens, so as to correct students' wrong cognition in time. When learning the key anatomical structure, teachers should timely put forward targeted problems related to clinical diseases ${ }^{[2]}$, guide students to think deeply and cooperate in exploration, in order to better help students master the anatomical structure, and cultivate their clinical thinking ability and comprehensive ability and literacy.

\section{Carrying out clinical advanced study and enhancing the compre- hensive quality of anatomy teachers}

As we all know, the learning quality of anatomy course of medical students largely depends on the teaching philosophy and teaching methods of professional teachers. In order to train the clinical thinking ability of medical students and improve their comprehensive quality, we must pay attention to optimizing the structure of anatomy teachers and strengthening the professional teachers. First of all, the purpose of introducing new and professional medical teachers is to improve the quality of young teachers ${ }^{[3]}$. Secondly, strengthen the training of on-the-job teachers. We should pay attention to guide anatomy teachers to establish the concept of lifelong learning, enrich their knowledge reserves and enhance their professional ability by participating in various continuing education training classes and all-round and multi angle learning; schools should also organize or encourage teachers to participate in various teaching and scientific research activities to grasp the latest research trends and progress of anatomy at home and abroad in real time; we should organize anatomy teachers and clinical teaching teachers to regularly cooperate to prepare lessons, discuss teaching plan and schedule, teach- ing content and mode, etc., so as to realize the mutual penetration and integration of the two courses, enhance the clinical thinking ability and level of anatomy teachers imperceptibly. At present, medical specialty in colleges and universities should strengthen cooperation with local hospitals, organize anatomy teachers to major hospitals, especially affiliated hospitals, for clinical observation and practice in winter and summer vacation ${ }^{[4]}$, national day and other holidays, and enrich their own clinical case material reserve through practice, so as to find the close relationship between anatomy and clinical medical knowledge in specific participation, summarizing and reflecting, to apply it to the follow-up teaching.

\section{Conclusion}

To sum up, the learning of anatomy knowledge aims to serve the follow-up clinical medical treatment, so it is very important to apply clinical thinking in anatomy teaching. Based on this, in the teaching of anatomy, teachers should actively change their concepts, correctly realize the importance of clinical thinking in anatomy teaching, and optimize the teaching mode from all aspects and angles, so as to cultivate students' clinical thinking ability.

\section{References}

1. Liao Y. Application of clinical thinking ability training in human anatomy teaching (in Chinese). Modern Vocational Education 2019; (24): 138-139.

2. He Y. The training of clinical thinking ability should be appropriately expanded in the teaching of human anatomy (in Chinese). Journal of Seeking Knowledge Guide 2019; (1): 70.

3. Liu J, Zhang X, Huang H. Training of clinical thinking in anatomy teaching (in Chinese). Basic Medical Education 2018; (2): 79-81.

4. Zhao Q, Zhang H, Zhang Z. Preliminary study on the combination of human anatomy teaching and clinical practice (in Chinese). Special Health 2018; (17): 179 . 